\title{
Gold Metallurgy in the Twelfth Century
}

\author{
THE DE DIVERSIS ARTIBUS OF THEOPHILUS THE MONK
}

\author{
Professor C. R. Dodwell
}

University of Manchester

The simple basic properties of gold - its colour, great malleability and ductility, and its immunity from oxidation even on melting-were well known in the ancient civilisations. In prehistoric times, in Egypt, Babylon and other lands of the Near East, the fabrication of gold articles was equally well understood, as the many brief references throughout the Old Testament establish. But for the first written treatise on the science and craft of working in gold we have to move on to medieval times in Europe and to the well-known manuscript compiled by the monk Theophilus.

Other medieval sources for the techniques of the period exist, but these consist mainly of miscellanies of hints and recipes, half magical and half scientific. Certainly none can hold up a candle to this source. None combines to the same extent the comprehensive range, the orderly presentation and the attention to detail. Theophilus' work embraces most of the contemporary skills and crafts, and gives detailed practical instructions based very clearly upon personal knowledge and experience. About three-quarters of the book is taken up with metal work and we have here, in fact, the earliest manuscript to describe the practical working of metal by a man who has actually carried out the operations. There are no other such sources until we come to the sixteenth century.
No original copy of Theophilus' work exists, but a number of copies made between the first half of the twelfth and the end of the fourteenth centuries are available. This page, from the manuscript in the British Museum, shows Book 3, Chapter LXXVII, 'De Solidando Auro et Argento Pariter' The Cladding of Silver with Gold. This copy of the mantuscript is in an early thirteentli-century German hand.
The treatise is divided into three Books, the first dealing with painting and the preparation of colour and pigments, the second with glass making, and the third and largest with metal work, including the working of iron, copper, bronze (a great deal of detail on bell founding), silver and gold. Each aspect of the subject of metal working is pursued logically, beginning with the kind of workshop to build, the construction of the furnace, the making of the crucibles, bellows and tools, and the nature and provenance of the metals to be used. A great part of the section dealing with gold is naturally concerned with the making of ecclesiastical ornaments, but the explicit instructions given are of wider interest to the presentday metallurgist.

Before we come to the details of his quite remarkable knowledge and his exposition of gold metallurgy, we should perhaps consider the background and period of activity of the author and later we shall try

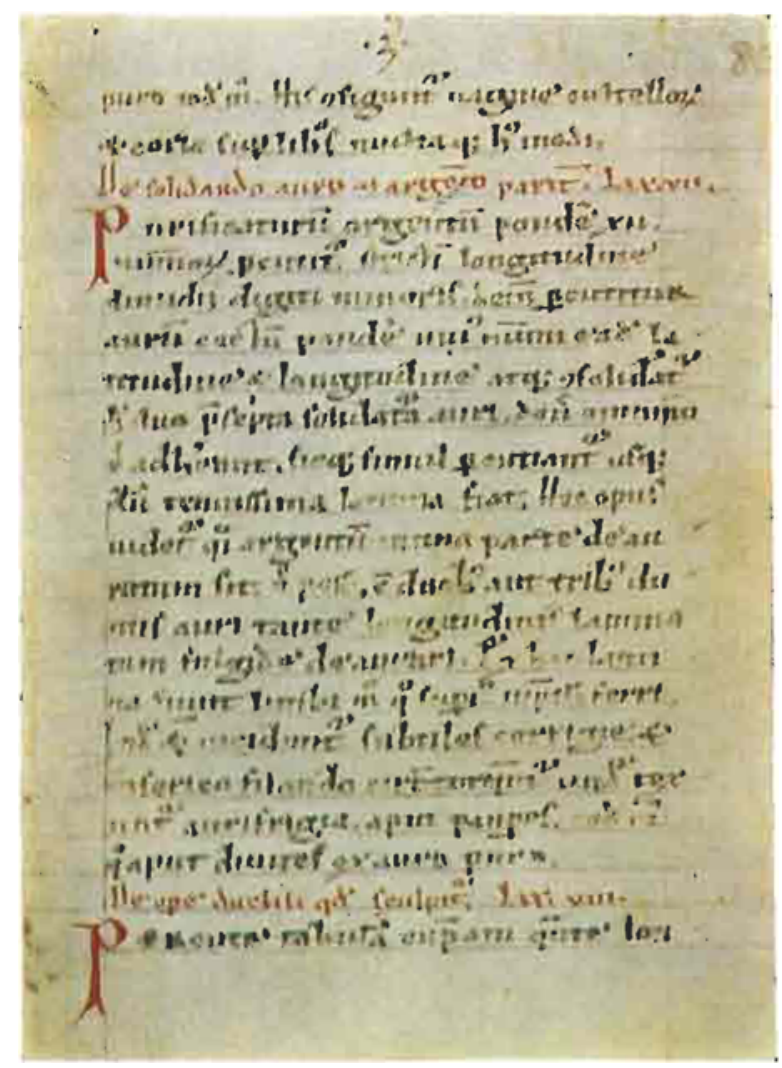




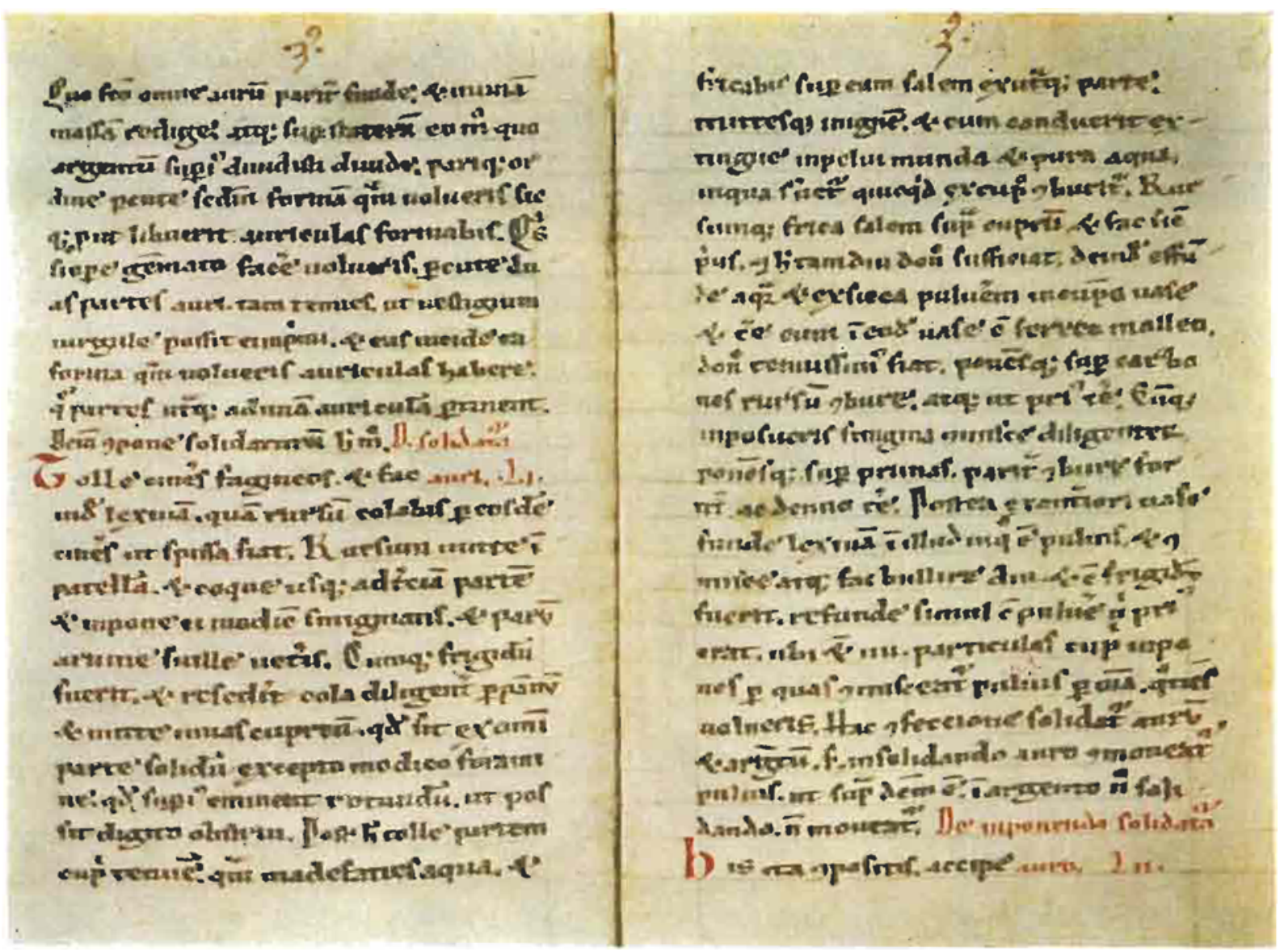

These two pages from the same manuscript show Book 3, Chapter LI, 'De Solidatura Auri'. They describe a flux for soldering gold compounded from beechwood ash, soap, hog's lard and copper chloride. It was used with a solder consisting of 25 per cent copper and 75 per cent gold.

to discover his actual identity. In this context, we should note that, though the original autograph text no longer exists, it can be reconstructed from a number of copies made at varying times between the first half of the twelfth and the end of the fourteenth centuries. This reconstruction, in fact, was made by the present writer some ten years ago ${ }^{\star}$ and it was in the course of this work that the following conclusions were arrived at.

The name Theophilus is of course a pseudonym and the use of it reflects the humble and unassuming character of the author, whose only direct reference to his personal background is that he is a priest and a monk. But there is good internal evidence, based upon an analysis of the theological and ecclesiastical attitudes expressed and upon the stylistic references, to suppose that he was writing in North-West Germany in the first half of the twelfth century, most probably between 1110 and 1140 . It is equally clear that he was himself a practising craftsman, and probably an artist of some standing among his contemporaries.

*Theophilus: De Diversis Artibus, translated from the Latin with Introduction and Notes, by C. R. Dodwell; London, Thomas Nelson, 1961.
Further he represented that unusual combinationan articulate craftsman: he could write well on his subject, and in fact he writes in a most stylish Latin.

\section{Gold Refining}

Now let us turn to the descriptions given by Theophilus of the refining and working of gold.

The partial refining of gold by cupellationmelting the gold with lead in a crucible made of bone ash and exposing the surface to air, when the base metal impurities were oxidised and removed-was known well before the Christian era, while the "cementation" method of removing some at least of the silver by interleaving thin plates of gold with mixtures containing salt and brickdust and heating for a long period to convert the silver to its chloride was rather vaguely described by both Strabo and Pliny in the first century A.D. Theophilus naturally gives an account of these two basic methods. Of cupellation he writes, under the chapter heading "How to Separate Gold from Copper":

Take the bones of some animal or other that you find in the street, burn them and, when they are cool, grind them to a fine powder. Mix with them a 
third part of beechwood ashes, and make crucibles as we have described in the refining of silver above. These you dry by the fire or in the sun. Then, carefully scrape the gold off the copper, and fold up the scrapings in a piece of lead that has been beaten thin. Place one of these crucibles on the embers in the front of the furnace, and, as soon as it is hot, put in it the lead wrapper with the scrapings, pile on the coals and blow. When the scrapings have melted, you burn them in the same way as one normally refines silver, now by removing the embers and adding lead, now by removing the scum and carefully blowing until the copper is completely taken up and the pure gold emerges.

On the treatment of gold to remove silver by the cementation process his description is the first really satisfactory account of the process. It runs:

Take any kind of gold, beat it into a thin leaf, three fingers wide and as long as possible, cut square pieces from it, put them evenly together and perforate them all with a fine file. Then take two earthenware crucibles, proved in fire and big enough for the gold to lie in. Break up a tile, or some baked red fireclay, very small, and weigh the powder into two equal parts, adding to it a third part of salt by weight. This is mixed with lightly sprinkled urine so that the ingredients do not stick together but are just moistened. Put a little of it - about the size of the gold - in one of the pots, then a piece of the gold, then the preparation and then the gold again, which is thus always covered by the preparation so that gold is not touched by gold. And so fill the crucible right up to the top. Cover it above with the other crucible, carefully lute them around with well-mixed and kneaded clay, and put it on the fire to dry: . . . In the morning take out the gold, cast it again and beat it, and place it in the kiln as before. After a day and a night, take it off again and, mixing a little red copper with it, melt it as before and replace it in the kiln. When you have removed it a third time, carefully wash it and dry it. Next weigh it and see how much is missing. Then fold it and keep it.

In addition to these well established processes, Theophilus describes for the first time a method of separating silver from gold by melting with sulphur, the silver forming easily reducible silver sulphide:

Place [the gold] in the crucible in which one normally melts gold and silver, and press a small linen cloth into the top so that nothing is accidentially blown out by the draught from the bellows. Place it in the front of the furnace and melt them. Then, add small pieces of sulphur in proportion to the amount of the scrapings, and carefully stir with a thin stick of charcoal until there are no more fumes. Immediately pour it into an iron mould.

Next, beat the metal lightly over the anvil to prevent any of the black part, burnt by the sulphur, from accidentally breaking off, because this is itself silver. For the sulphur eats none of the gold, but only the silver, which in this way it separates from the gold, and which you must carefully keep. Melt this gold again in the same crucible as before, and add sulphur. When it has been stirred and poured out, break up and keep the black residue and so continue until the gold emerges pure.

Then, put all the black residue, which you have carefully retained, in the pot made from bone and ashes, add lead and heat it so that you recover your silver.

\section{The Properties of Gold}

Theophilus appears not to have recognised one of the most characteristic properties of gold - its exceptionally high specific gravity - but he was certainly aware of its complete immunity from oxidation when in the pure state. He describes for example a very precious Arabian gold which is of an exceptionally red colour:

Modern workmen counterfeit its appearance by adding a fifth part of red copper to pale gold, and they deceive many unwary people. This can be guarded against in this way. The gold is put in the fire and, if it is pure, it does not lose its brightness. If, however, it is adulterated, it completely changes colour.

The troubles that can beset the refiner or foundryman in the casting of his metals were apparently also well understood by Theophilus. "When you first cast gold", he writes,

examine it, by carefully scraping and scratching around it, in case there happens to be any airbubble or crack in it. This often happens when, through the carelessness, or negligence, or ignorance, or lack of skill of the founder, it is cast either too hot or too cold, or too quickly, or too slowly. If, when you have cast it with care and circumspection, you perceive a flaw of this kind in it, carefully dig it our, if you can, with a suitable tool. But, if the bubble or crack is so deep that you cannot dig it out, you must cast again until it is sound.

\section{Gold Solders and Fluxes}

One of the most interesting and intriguing parts of the manuscript is that describing the methods of soldering gold. In fact two quite distinct techniques are given, one for use in the construction of articles such as chalices and censers, and one for the repairing of work that has been fractured or pierced through ignorance or negligence, although for once there is some little confusion in the manuscript between the two methods. In the former method a gold brazing alloy rather like that used today is employed:

Melt a little gold and mix it with a third part of pure red copper which has been similarly melted. When this has been lightly beaten, you reduce it completely to filings.

The soldering flux is then to be prepared as described in the passage reproduced on page 52 . This reads as follows : 
Take some beechwood ash, make a lye of it, and strain this again through the same ash so that it becomes thick. Replace it in the pot and heat it until it is reduced to a third of its bulk, and add to it a little soap and a little old hog's lard. When it is cool and has set again, strain it carefully through a cloth, and put it in a copper vessel. . . . After this, take a thin piece of copper, moisten it in water, and run salt over it on each side. Put it on the fire and, when it is red hot, quench it with pure water in a clean basin, in which you should keep whatever comes off the copper in the burning. Rub salt again over the copper and proceed as before, and do this until you eventually have enough. Then pour off the water, and dry out the powder in a copper vessel, and grind it in the same vessel with an iron pestle until it becomes very fine. Place it on the fire to heat again and grind as before. Put some soap in, mix it carefully, then put it on the fire, warm evenly and grind anew.

Afterwards, pour the lye from the former pot into the one containing the powder, mix and boil for a long time. When it is cold, pour it back together with the powder into its original container. In this you also insert four pieces of copper, with which you mix the powder everywhere whenever you want to stir.
Now, bearing in mind that at this time mineral acids were unknown and that compounds such as copper chloride could not readily be prepared, it is fascinating to contemplate the compounding of this flux.

We have, of course, no indication of the proportions of each constituent, but clearly the flux comprised a thin slurry whose solid fraction consisted of copper carbonate, copper stearate and possibly copper oleate, its liquid fraction being a solution of the chlorides of sodium, potassium, magnesium and copper. When used with the 25 per cent copper, 75 per cent gold solder, this would perform the function of a normal soldering flux, but in another passage describing the making of settings for precious stones there is no mention of solder. Thin gold wires are attached to the body of the gold vessel merely by repeated heating together in the presence of the flux described above, so that the flux itself became the joining medium.

The only reasonable explanation of this is that when the flux was heated a small quantity of finely dispersed metallic copper was precipitated in the joint area. A diffusion bond would then have

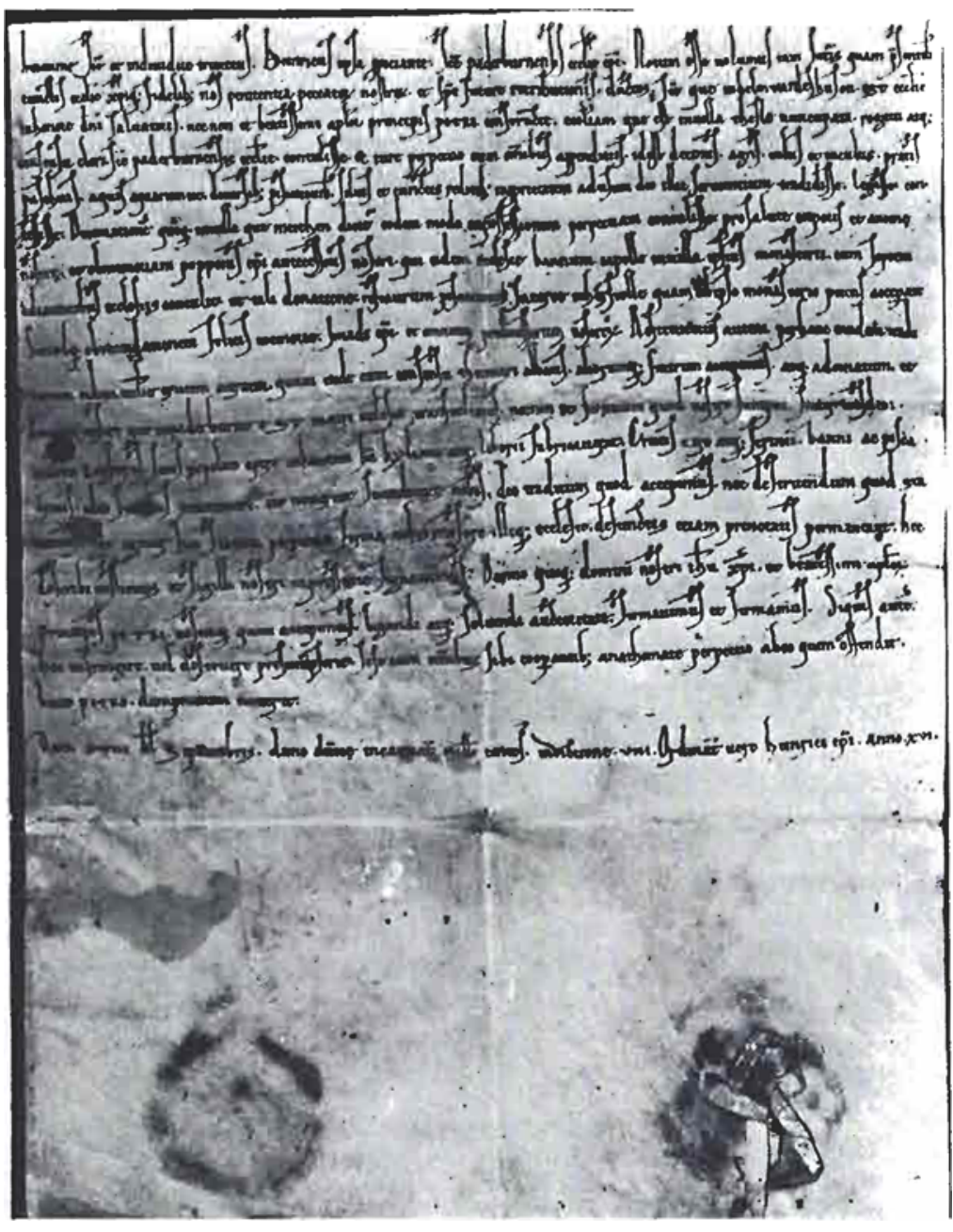

A document, dated August 15th, 1100 in the episcopal archives of Paderborn in which Henry of Werl, the Bisliop of Paderhorn, makes over to the monastery at Helmarshausen a chureh and tithes in return for a gold cross and coffer "which, at our expense, Brother Roger of the same church had made by skilled craftsmanship". It is quite possible that this Roger of Helniars" hausen and Theophilus or Roger, the author of the manuscript, were identical. 


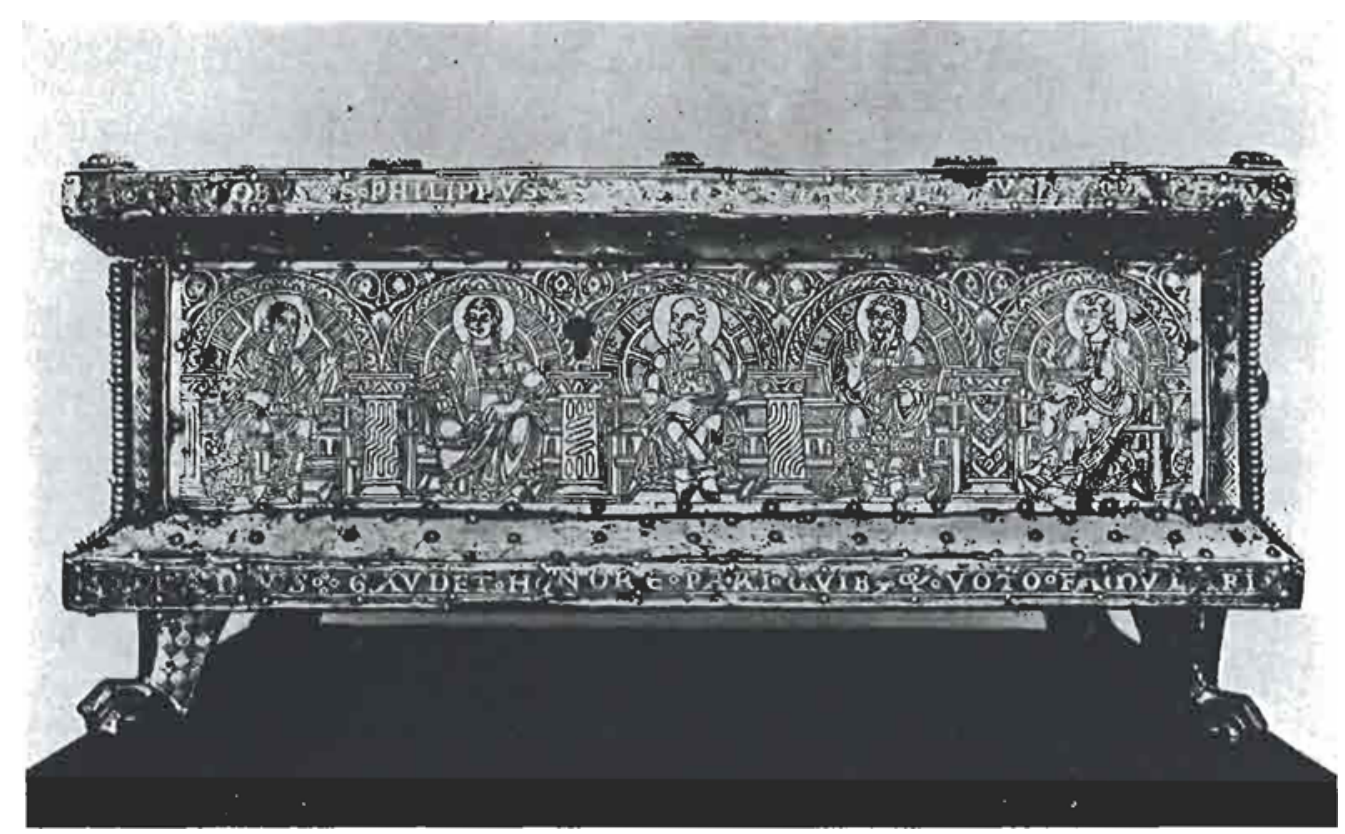

Roger's gold cofier or portable altar in the cathedral at Paderborn. This shows a mastery of many of the techniques of the metal worker described by Theophilus.

been formed, but the repeated heating would have been necessary to consolidate the copper deposit and to bond it firmly to the gold. This method would have enabled subsequent soldering operations to have been carried out on the same article by using the lower melting solder alloy.

What remains a little difficult to understand is the use, described in a later passage, of a quite simple flux (consisting basically of sodium chloride and potassium carbonate) made by burning winestone and mixing with salt and water. This was to be used with the copper-gold solder in the repairing of broken pieces of repoussé work.

\section{Gold Cladding}

The advantages of the cladding or metallurgical bonding of a surface layer of gold on to a sheet of less precious material were recognised by Theophilus, for this enabled him to produce engraved and die-stamped borders for ecclesiastical objects at less expense than if they were made in solid gold. The instructions for cladding, reproduced in the illustration on page 51 , read in translation:

Silver, weighing twelve nummi, ${ }^{\star}$ is refined and beaten to a narrow shape, half the length of the little finger. Then, heated gold, weighing one nummus, is beaten to the same width and length. These two are joined together with the flux for gold, already described, until they are completely fast, and then they

*According to Agricola in De Re Metallica (1556) the goldsmiths of Cologne and Antwerp divided the bes, the old Roman unit of weight, into 12 nummi. The nummus would therefore have a weight of a little over half an ounce Troy or say 16 grams. are beaten together like this until a very thin plate is made. On one side, this work looks like gilt silver, yet a plate of such a size cannot be so brightly gilded with two or three nummi of gold.

\section{The Identity of Theophilus}

While there are no means available to us of establishing firmly the identity of Theophilus there is none the less some evidence to provide quite a reasonable guess. The earliest surviving manuscript (itself probably dating from the writer's lifetime) tells us that the author's name was Theophilus or Roger. Now during the first part of the twelfth century there was a monk known as Roger in the monastery of Helmarshausen on the River Weser in Hesse. Moreover, this foundation was one of the most important centres of art and gold-smithing in NorthWest Germany, providing works of art for the princes and bishops of the time. There is a reference to this Roger of Helmarshausen in a deed dated 1100 , concerning a gold cross and a reliquary or coffer which he made for the Bishop of Paderborn, and the latter still exists in the form of a portable altar in the cathedral there.

Another similar altar made by Roger in 1118 is also preserved in the church of St Francis in Paderborn.

Our knowledge of this man is so fragmentary, and our knowledge of the author of the treatise so circumstantial, that a firm identification is not to be expected, but it is not wholly impossible or unlikely that the "De Diversis Artibus" represents the life's experience of Roger of Helmarshausen - monk and goldsmith-set down in the evening of his days. 